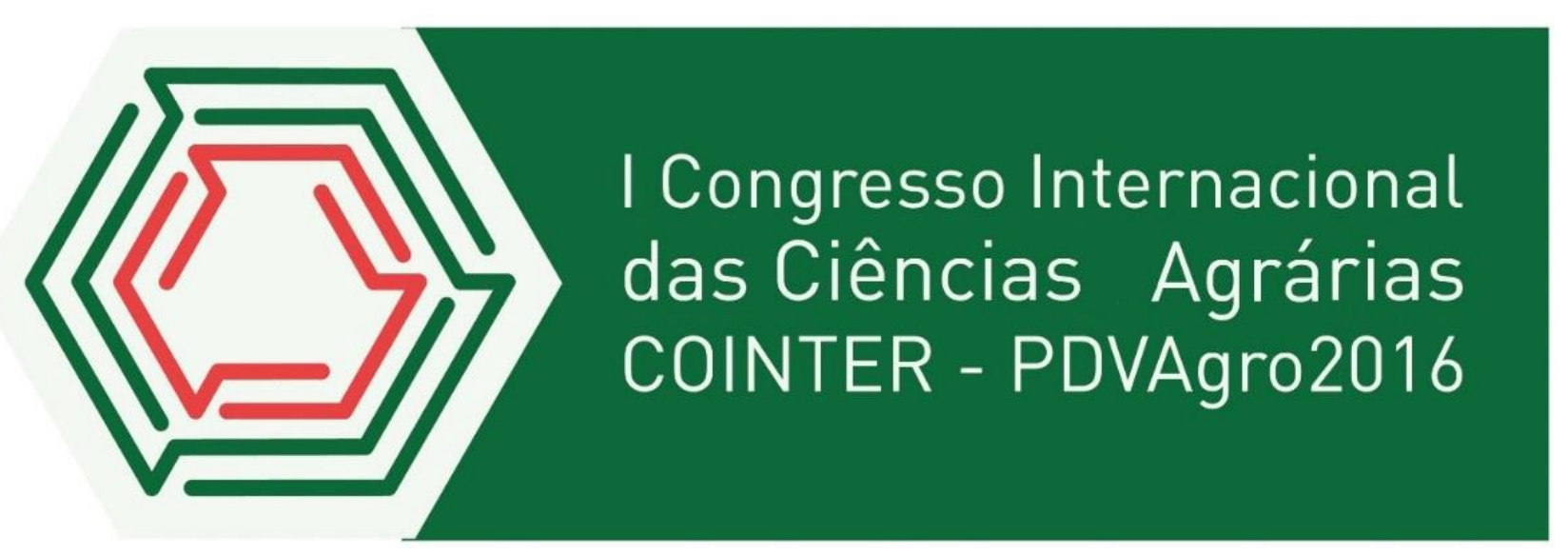

\title{
ANÁLISE DE PERSPECTIVAS SOBRE A INTERNACIONALIZAÇÃo ATRAVÉS DO TESTE DE MATRIZ DE REPERTÓRIO
}

\author{
Apresentação: Comunicação Oral \\ Elielma Josefa de Moura ${ }^{1}$; Kaline Soares da Silva ${ }^{2}$; Carolayne Silva de Souza ${ }^{3}$; Kilma da Silva \\ Lima Viana ${ }^{4}$; Erick Viana da Silva ${ }^{5}$
}

\begin{abstract}
Resumo
O trabalho tem como objetivo fazer uma análise de como se deu o processo de institucionalização da internacionalização no Instituo Federal de Pernambuco, através da análise de documentos norteadores dessa política e, através da aplicação da Matriz de Repertório de Kelly, com uma professora de línguas que esteve presente ocupando um cargo de gestão, durante a transição de Escolas Agrotécnicas Federais para Institutos Federais. O instrumento de coleta de dados utilizado foi o Teste de Matriz de Repertório de George Kelly. O trabalho tem fundamentação na Teoria institucional, que busca entender a institucionalização de uma instituição. A pesquisa foi composta de dois momentos, análise documental, e formulação da percepção da professora de línguas estrangeiras sobre a internacionalização. Pode-se observar que a política de internacionalização está presente em muitos documentos, no entanto é pouco ativa dentro da instituição.
\end{abstract}

Palavras-Chave: institutos federias, internacionalização, teoria institucional, teste de matriz de repertório de George Kelly

\section{Introdução}

A mudança de Escolas Agrotécnicas Federais (EAF's), para Institutos Federais (IF's), aconteceu no ano de 2008 com a publicação da Lei No 11.892, de 29 de dezembro de 2008, na qual foi instituída a Rede de Educação Profissional, Científica e Tecnológica e criação dos Institutos Federais de Educação, Ciência e Tecnologia. No decorrer do período de transição para IF's, foram criados documentos relacionados com o processo de internacionalização, com o objetivo de quantificar e realizar metas dentro de áreas estratégicas e, com a finalidade de elaboração de políticas institucionais.

\footnotetext{
${ }^{1}$ Agronomia, IFPE, elielmamoura@outlook.com

2 Agronomia, IFPE, kalis.soares8@gmail.com

${ }_{3}^{3}$ Agronomia, IFPE, carol.silva452@gmail.com

${ }^{4}$ Professora de Licenciatura em Química, IFPE, kilma.viana@ vitoria.ifpe.edu

${ }^{5}$ Professor de Administração, IFPE, erick.viana@vitoria.ifpe.edu.br
} 
Entre esses documentos criados com a finalidade de institucionalizar a internacionalização, podemos mencionar o PDI (Plano de Desenvolvimento Institucional), o CELE (Centro de Línguas Estrangeiras), que foi criado para desenvolver ações que se refiram a internacionalização, tais como, cursos de línguas estrangeiras para estudantes e servidores do IFPE.

Para se entender o papel das organizações, faz-se necessário entender a institucionalização e todo o processo envolvido na formação da instituição (CORAIOLA; BARATTER; TAKAHASHI, 2011), por isso, o trabalho está fundamentado na Teoria Institucional e, tem como objetivo analisar a perspectiva de uma professora de línguas que fez parte do processo de transição para Institutos, enquanto ocupava um cargo na área de gestão no IF, para que falasse de sua perspectiva sobre de que maneira se deu esse processo de institucionalização da internacionalização.

O instrumento de coleta de dados utilizado foi o Teste de Matriz de Repertório de Kelly (TMR), que está fundamentado na Teoria dos Construtos Pessoais (TCP). Segundo a TCP as pessoas que aprendem ou vivenciam um conceito não necessariamente, saberão a mesma coisa, porque podem ter tido bases anteriores diferentes que resultou na construção do determinado ponto de vista com opiniões diferentes (VIANA, 2014). George Kelly, desenvolveu o Teste de Matriz de Repertório através de estudos sobre construtos pessoais, com objetivo de investigar sistemas de antecipação relacionando-os com outros elementos.

Destacamos a relevância deste trabalho, entender como seu deu a política de internacionalização dentro dos Institutos, através de análise dos documentos norteadores e, através da aplicação do TMR com o sujeito da pesquisa.

\section{Fundamentação Teórica}

O âmbito dos estudos organizacionais passou por desenvolvimentos ao longo do tempo, onde foram construídas teorias com o foco de compreender as organizações. A perspectiva dos estudos organizacionais surge como uma alternativa a estudos, que, consideram as organizações influenciadas por fatores externos. Para se entender o papel das organizações, faz-se necessário entender a institucionalização e todo o processo envolvido na formação da instituição (CORAIOLA; BARATTER; TAKAHASHI, 2011).

$\mathrm{O}$ isomorfismo institucional diz que, para que as organizações possam enfrentar situações em contextos similares as outras, elas devem procuram se legitimar, e se assemelhar as demais. Desse modo poderá promover um encaixe no contexto em que estão inseridas, através de práticas e 
procedimentos rotineiros, para se tornarem homogêneas, podendo mudar suas características, tendendo a se tornarem isomórficas de acordo com o ambiente que estão inseridas.

Dessa forma, quando a organização se "iguala" a outra já legitimada, ela pode conseguir uma menor possibilidade de fracasso. Segundo Dimaggio e Powell (2005), quanto mais uma organização se institucionaliza, mais semelhante ela se torna.

O isomorfismo não consiste em um fenômeno totalizante. Se define como sendo múltiplas práticas e estruturas adotadas, que variam de intensidade de acordo com o conjunto e objetivo das organizações, que tendem a crescer na medida em que as práticas adquiram legitimidade (CORAIOLA; SILVA, 2008). As organizações em certos campos, se transformam a fim de se tornarem similares com organizações do seu tipo, respondendo rapidamente a transformações externas ou, após um determinado período de tempo. Dependendo da necessidade de dependência de uma organização a outra, esta, poderá se tornar mais similar, em termos comportamentais, ou estruturais.

\section{Metodologia}

A pesquisa apresentou dois momentos: em um primeiro momento foi feita uma análise documental, quando foram analisados documentos oficiais do IFPE, relativos à internacionalização. E um segundo momento, quando foi aplicado o Teste de Matriz de Repertório de Kelly com uma professora de língua estrangeira (sujeito da pesquisa), que ocupava cargo de gestão no IFPE durante o período de transição, com o intuito de se compreender como seu deu a política de internacionalização no Instituto. O campo de Pesquisa foi constituído por um Campus do Instituto Federal de Pernambuco, que se encontrava na condição de Escola Agrotécnica Federal quando da criação dos Institutos Federais.

Foi submetida ao Teste de Matriz de Repertório (TMR) uma professora de língua inglesa que esteve presente durante o processo de mudança de EAF para IF, com a finalidade que ela falasse como se deu o processo de internacionalização durante esse momento de transição, baseado nas experiências que ela vivenciou sobre a internacionalização dentro do Instituto, com base nos seus construções pessoais.

$\mathrm{Na}$ operacionalização do TMR foi solicitado ao sujeito que elencasse elementos diante da pergunta “O que você pensa quando falamos em internacionalização?”. Os elementos elencados são nomeados com (E1, E2, E3...) de acordo com a ordem em que foram evocados pelo sujeito, e que na 
Matriz estão dispostos de forma horizontal e, os construtos na vertical, dispostos em dois polos, o polo emergente (à direita) e o polo de contraste (à esquerda).

Os polos emergentes e os polos de contrastes dos construtos foram identificados seguindo pela ordem da enumeração dos elementos. Por exemplo, foram escolhidos os três primeiros elementos, E1, E2 e E3 e pedido para a entrevistada relacionar dois que se aproximarem, e diferir do terceiro elemento que formava a tríade. Os dois elementos semelhantes formam o polo emergente, e o terceiro o polo de contraste. Na Matriz esses três elementos escolhidos estão destacados em cor vermelha.

Após essa etapa, é solicitado ao sujeito da pesquisa que localize os elementos restantes, e utilize uma escala, que vai de 1 a 5 para fazer o seu posicionamento. Os elementos podem ser localizados no polo emergente (1), próximo ao polo emergente (2), intermediário (3), mais próximo ao polo de contraste (4), ou localizado no polo de contraste (5). Também pode ocorrer de o sujeito achar um elemento fora do contexto de ambos os polos, e nomeá-lo, com (-3).

Esse procedimento de unir dois elementos semelhantes e diferir de um terceiro elemento pode ser realizados inúmeras vezes, utilizando-se de diversas combinações, até o sujeito não conseguir fazer mais as correlações. A análise da Matriz, é feita através das correlações entre construtos e entre os elementos, que permitem compreender de qual maneira um determinado elemento ou construto está ligado ao outro. Nem todas as correlações são significativas, aparecem no gráfico, aquelas com uma correlação acima de 0,5 , da qual é considerada uma correlação forte. 


\begin{tabular}{|c|c|c|c|c|c|}
\hline Construtos & $\begin{array}{c}\text { Polo } \\
\text { Emergente }\end{array}$ & $\begin{array}{c}\text { E1 Política } \\
\text { Institucional }\end{array}$ & $\begin{array}{c}\text { E2 Inserção } \\
\text { do estudante }\end{array}$ & $\begin{array}{c}\text { E3 } \\
\text { Ampliação } \\
\text { do universo } \\
\text { do estudante }\end{array}$ & $\begin{array}{c}\text { E4 } \\
\text { Intercâmbio } \\
\text { com } \\
\text { diferentes } \\
\text { culturas }\end{array}$ \\
\hline C1 Resultados & Fim & $\mathbf{5}$ & $\mathbf{1}$ & $\mathbf{1}$ & 2 \\
\hline $\begin{array}{c}\text { C2 } \\
\text { Desenvolvimento }\end{array}$ & Profissional & 1 & 3 & 5 & 5 \\
\hline C3 Instrumento & Aprendizagem & 5 & 1 & 1 & 2 \\
\hline $\begin{array}{c}\text { C4 } \\
\text { Intencionalidade }\end{array}$ & Formação & 4 & 5 & 1 & 1 \\
\hline $\begin{array}{c}\text { C5 } \\
\text { Empoderamento }\end{array}$ & Social & 1 & 3 & 4 & 5 \\
\hline $\begin{array}{c}\text { C6 Nivel de } \\
\text { Implementação }\end{array}$ & Alta Gestão & 1 & 2 & 4 & -3 \\
\hline C7 Justiça social & Estudante & 1 & 1 & 1 & 2 \\
\hline C8 Execução & $\begin{array}{c}\text { Gestão de } \\
\text { pessoas }\end{array}$ & 4 & 5 & -3 & 5 \\
\hline
\end{tabular}

Tabela 2: Continuação da Matriz de Repertório de Kelly do sujeito da pesquisa. IFPE, 2016. Elaboração dos autores.

\begin{tabular}{|c|c|c|c|c|c|}
\hline $\begin{array}{c}\text { E5 } \\
\text { Crescimento } \\
\text { do estudante }\end{array}$ & $\begin{array}{c}\text { E6 } \\
\text { Mobilidade } \\
\text { Social }\end{array}$ & $\begin{array}{c}\text { E7 Igualdade } \\
\text { de } \\
\text { oportunidade }\end{array}$ & $\begin{array}{c}\text { E8 Ampliação das } \\
\text { relações } \\
\text { Interinstitucionais }\end{array}$ & $\begin{array}{c}\text { E9 } \\
\text { Formação } \\
\text { continuada } \\
\text { dos } \\
\text { servidores }\end{array}$ & $\begin{array}{c}\text { Polo de } \\
\text { Contraste }\end{array}$ \\
\hline 1 & 2 & 3 & 5 & 2 & Meio \\
\hline 1 & 1 & 3 & 1 & 3 & Pessoal \\
\hline 2 & 2 & 1 & 5 & 1 & $\begin{array}{c}\text { Estratégia de } \\
\text { Gestão }\end{array}$ \\
\hline 1 & 4 & 4 & 3 & 1 & $\begin{array}{c}\text { Resgate } \\
\text { Social }\end{array}$ \\
\hline 5 & 1 & 1 & 1 & 5 & Individual \\
\hline-3 & -3 & 2 & 1 & 5 & Operacional \\
\hline 1 & 1 & 1 & -3 & 5 & Servidor \\
\hline 5 & -3 & 1 & 5 & 1 & ARINTER \\
\hline
\end{tabular}

Gráfico 1: Correlações entre os elementos do TMR do sujeito da pesquisa. IFPE, 2016. Elaboração dos autores. 


\section{Gráfico das Correlações entre Elementos}

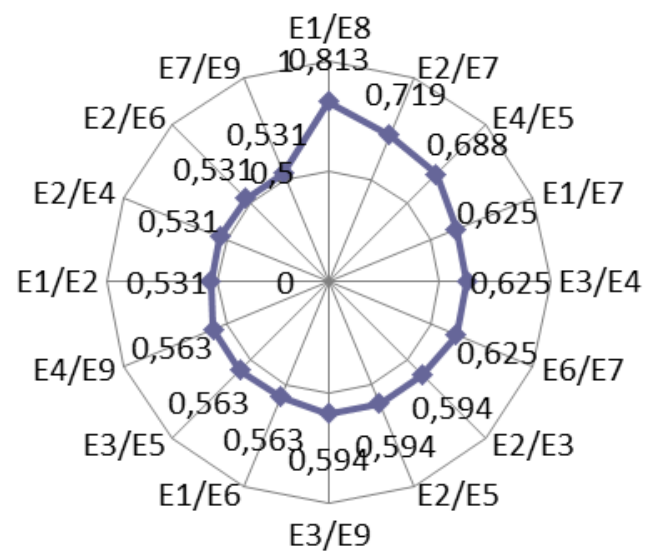

Gráfico 2: Correlações entre os construtos TMR do sujeito da pesquisa. IFPE, 2016. Elaboração dos autores.

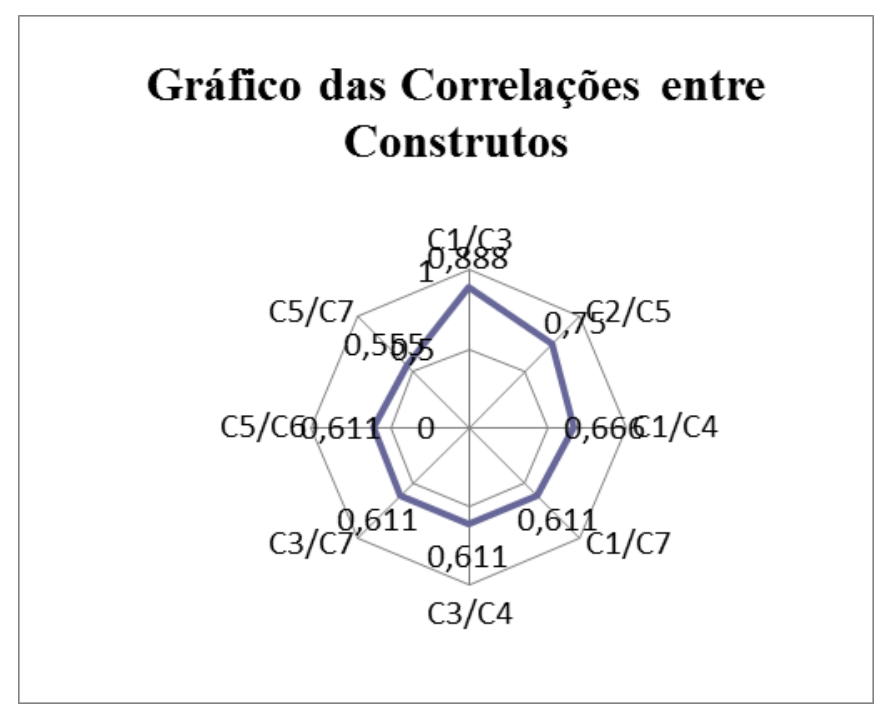

De acordo com a Matriz os elementos que, em ordem, foram elencados e permitiram a construção dos construtos foram: E1-Política institucional; E2-Inserção do estudante; E3Ampliação do universo do estudante; E4-Intercâmbio com diferentes culturas; E5-Crescimento do estudante; E6-Mobilidade social; E7-Igualdade de oportunidade; E8-Ampliação das relações interinstitucionais; E9-Formação continuada dos servidores. Os construtos formulados foram: C1Resultados; C2-Desenvolvimento; C3-Instrumento; C4-Intencionalidade; C5-Empoderamento; C6Nível de implementação; C7-Justiça social; E8-Execução.

\section{Resultados e Discussão}

Um outro momento da pesquisa foi a aplicação do Teste de Matriz de Repertório de George 
Kelly, que após ter sido aplicada com a professora de línguas, foram obtidos correlações entre construtos e elementos, onde foi possível ser formulada a percepção da mesma acerca da internacionalização no IFPE.

A partir da observação dos gráficos da Matriz, são formados agrupamentos que possuem uma forte correlação. Os agrupamentos são formados do gráfico das correlações dos construtos, como também das correlações dos elementos. Temos como exemplo, o agrupamento dos elementos que possuíram forte correlação e, apresentaram significância maior que 0,5 para poderem aparecerem no gráfico: E2;E7 / E7;E1 / E1;E6 / E6;E2, podendo serem formados mais de um agrupamento.

E2;E7: Inserção dos estudantes; Igualdade de oportunidades. E7;E1: Igualdade de oportunidades; Política institucional. E1;E6: Política institucional; Mobilidade social. E6;E2: Mobilidade social; Inserção do estudante. Nesse agrupamento de correlações, o sujeito deixa explícito a necessidade da inserção do estudante dentro de políticas institucionais acerca da internalização, e da igualdade que eles devem ter com professores, servidores, nesse processo. Agrupamento dos construtos: C1;C3 / C3;C7 / C7C1. C1;C3: Resultados; Instrumento. C3;C7: Instrumento; Justiça social. C7;C1: Justiça social; Resultados.

Além das discursões do TMR, foi feita uma análise documental, onde a partir de documentos como o FORINTER (Fórum de Relações internacionais dos Institutos Federais) pudemos observar a função que tem os Institutos Federais de criar redes de cooperação, para assim, fazer trocas de conhecimento e experiências. E também, ver a relevância que as políticas de internacionalização tem dentro dos IF's.

Para que haja a execução de tais trabalhos de internacionalização dentro dos IF's, é necessário inclusão e implementação de políticas de internacionalização junto à comunidade acadêmica. Podemos verificar, também, na perspectiva do sujeito participante, a necessidade da presença das relações internacionais como instrumento de inclusão.

Ao serem investigados editais de Projetos ou Programas de Extensão no IFPE acerca da internacionalização, foi verificado apenas a presença de dois Programas Internacionais cadastrados no IFPE Campus Vitória de Santo Antão. Programa Internacional Despertando Vocações para Licenciaturas (PDVL) e para as Ciências Agrárias (PDVAGRO). 
$\mathrm{Na}$ análise da opinião do sujeito da pesquisa percebemos que a política de internacionalização tem forte relação com a inserção do estudante, igualdade de oportunidades, formação continuada de servidores, ampliação do universo do estudante, políticas institucionais e mobilidade social.

\section{Conclusões}

De acordo com a perspectiva analisada na coleta de dados, e com a análise documental podemos perceber que o processo de internacionalização, na perspectiva do sujeito participante, é proposto em diversos documentos institucionais, no entanto, não é executado da maneira esperada. O sujeito entende a internacionalização como um dos meios para alcance da função social da instituição ao promover a inclusão, mobilidade social e formação continuada dos servidores. Há pouca divulgação sobre a política de internacionalização do IFPE, barreiras, desigualdades de oportunidades que impedem que o processo da internacionalização aconteça.

A partir dessas discussões, podemos verificar a necessidade de haver uma ampla divulgação das políticas de relações internacionais, como uma condição necessária para um bom desenvolvimento da internacionalização dentro da instituição. O conhecimento acerca dessas políticas, poderá provocar maior interesse da comunidade pela troca de conhecimentos e experiências e, a partir daí, o usufruto de possibilidades concretas de efetivação dos objetivos institucionais já previstos nos documentos oficiais.

\section{Referências}

BRASIL, FÓRUM DE RELAÇÕES INTERNACIONAIS DOS INSTITUTOS FEDERAIS, p.4. Brasília, 2009.

CORAIOLA, D. M.; BARATTER, M. A.; TAKAHASHI, A. R. W. Isomorfismo institucional e decisão estratégica: o caso dos cursos superiores de tecnologia (CST's) da OPET. V Encontro de Estudos em Estratégia, Porto Alegre, maio, 2011. $17 \quad$ p. (http://www.anpad.org.br/diversos/trabalhos/3Es/3es_2011/2011_3ES166.pdf)

CORAIOLA, D. M.; SILVA, C. L. M. Discurso organizacional e isomorfismo institucional: as mudanças gráficas em jornais brasileiros. Revista Eletrônica de Ciência Administrativa, Paraná, v. 7, n.2, p. 1-13, nov, 2008. (http://www.spell.org.br/documentos/ver/5182/discurso-organizacionale-isomorfismo-institucional--as-mudancas-graficas-em-jornais-brasileiros)

DI MAGGIO, P. J.; POWELL, W. W. A gaiola de ferro revisitada: isomorfismo institucional e racionalidade coletiva nos campos organizacionais. Revista de Administração de Empresas, vol. 45, 
n. 2, abr-jun 2005. Rae-Clássicos. (http://rae.fgv.br/sites/rae.fgv.br/files/gaiola-ferro-revisitadaisomorfismo-institucional-racionalidade-coletiva-nos-campos-organizacionais_0.pdf)

VIANA, K. S. L. Avaliação da experiência: uma perspectiva de Avaliação para o ensino das Ciências da Natureza. 2014. 226 f. Tese (Doutorado em Ensino das Ciências) - Programa de PósGraduação em Ensino das Ciências da Universidade Federal Rural de Pernambuco, Recife. 